\section{The Making of a Rostro-carinate Flint Implement.}

BY the courtesy of Sir Hercules Read, K.C.B., I have now been able to exhibit in the case at the British Museum containing the sub-Red Crag rostrocarinate implements a specimen which I have myself flaked, using an ordinary flint pebble as a hammerstone, into this definite and peculiar form.

It was only after a very careful and prolonged study of one of the sub-Crag implements that I was able to recognise the plan upon which the ancient men had worked, and, after many failures, to produce a true rostro-carinate type.

I found it to be necessary to select a potato-shaped nodule of flint, and to detach a flake from one end of it, and in such a manner as to produce the ventral plane (Fig. I). Then, having by this means got a flaking surface, I was able to remove flakes on either side of this surface and to produce the typical "keel" or carina (Fig. 2).

I may say that unless the nodule of flint is held in a particular manner when being struck the flakes detached will not be taken off at the required angle, and no "Keel" will be formed.

When this "keel" is produced the flint must be undercut or cleared at the point X (Fig. 3) to form the actual overhanging "beak."

This is a very difficult task, as if a careless blow is given the end of the implement is broken off, and it is useless, a fact continually impressed upon one when making these rostro-carinate specimens. The only means of avoiding the necessity for undercutting is to detach the primary flake of such a concave shape that the necessary overhang is produced (Fig. 4).
11

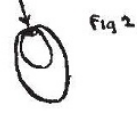

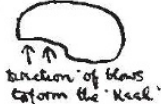

fig ?

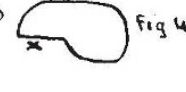

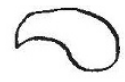

Careful flaking will then give the "keel," and the rostro-carinate implement be complete.

$I$ find it is sometimes necessary to detach flakes from the dorsal as well as the ventral surface to get the required form, and an examination of the subCrag specimens shows that their makers were occasionally compelled to adopt this method.

It was also noticed that some of the sub-Crag pieces when held with the "beals" towards one exhibited a curious one-sided appearance, which puzzled me greatly for some time.

I was also very surprised to find the specimens of my own manufacture also showed this same peculiarity. I have now found that this is due to the fact that flakes of unequal size and thickness are taken off from the two sides respectively when forming the "keel," which causes one side to get more hollowed out than the other, and the asymmetrical appearance to be produced.

I hope this description of the rostro-carinate flints will convince archæologists that we are dealing with a very complex type of implement, and that such a highly specialised tool cannot very well have been produced by unguided, haphazard natural forces.

I2 St. Edmund's Road, Ipswich, November 8.

\section{On an Apparent Fallacy in the Statistical Treatment of "Antedating" in the Inheritance of Pathological Conditions.}

THE problem of the "antedating" of family diseases is one of very great interest, and is likely to be more studied in the near future than ever it has been in NO. 2247 , vOL. 90] the past. The idea of antedating, i.e. the appearance of an hereditary disease at an earlier age in the offspring than in the parent has been referred to by Darwin, and has no doubt been considered by others before him. Quite recently, studying the subject on insanity, Dr. F. W. Mott speaks of antedating or anticipation as "nature's method of eliminating unsound elements in a stock" " Problems in Eugenics," papers communicated to the First International Eugenics Congress, I912, p. 426).

I am unable to follow Dr. Mott's proof of the case for antedating in insanity. It appears to me to depend upon a statistical fallacy, but this apparent fallacy may not be real, and I should like more light on the matter. This is peculiarly desirable, because I understand further evidence in favour of antedating is soon forthcoming for other diseases, and will follow much the same lines of reasoning. Let us consider the whole of one generation of affected persons at any time in the community, and let $n_{8}$ represent the number who develop the disease at age $s$, then the generation is represented by-

$$
n_{0}, n_{1}, n_{2} \ldots n_{3} \ldots n_{100}, \text { say. }
$$

Possibly some of these groups will not appear at all, but that is of little importance for our present purpose.

Let us make the assumptions (I) that there is no antedating at all; (2) that there is no inheritance of age of onset; thus each individual reproduces the population of the affected reduced in the ratio of $p$ to $\mathrm{I}$. Then the family of any affected person, whatever the age at which he developed the disease, would represent on the average the distribution-

$$
p n_{0}, p n_{1}, p n_{2} \ldots p n_{s} \ldots p n_{100} \text {. }
$$

The sum of such families would give precisely the age distribution at onset of the preceding generation.

Now let us suppose that for any reason certain of the groups of the first generation do not produce offspring at all, or only in reduced numbers. Say that $q_{s}$ only of the $n_{s}$ are able to reproduce their kind; then of the older generation, limited to parents, the distribution will be-

$$
q_{0} n_{0}+q_{1} n_{1}+q_{2} n_{2}+\ldots+q_{s} n_{8}+\ldots+q_{100} n_{100},
$$

but the younger generation will be-

$$
p\left(q_{0}+q_{1}+\ldots+q_{8}+\ldots+q_{100}\right)\left(n_{0}+n_{1}+\ldots\right.
$$

i.e. the relative proportions will remain absolutely the same.

The average age at onset and the frequency distribution of the older generation, that of the parents, will be entirely different from that of the offspring, and will depend wholly on what values we give to the $q$ 's. If frequency curves be formed of the two generations they will differ substantially from each other. This difference is not a result or a demonstration of any physiological principle of antedating, but is solely due to the fact that those who develop the disease at different ages are not equally likely to marry and become parents.

A quite striking instance of the fallacy, if it be such, would be to consider the antedating of "violent deaths." Fully a quarter such deaths in males, nearly a half in females, occur before the age of twenty years. Consider now the parents and offspring who die from violent deaths; clearly there would be no representative of death from violence under twenty in the parent generation, and we should have a most marked case of antedating, because the offspring generation would contain all the infantile deaths from violence.

In the case of insanity, is the man or woman who develops insanity at an early age as likely to become 